\title{
The Suh Muscle Hook: A New Muscle Hook for Tight Extraocular Muscles during Strabismus Surgery
}

\author{
Lin Luo', Linda A. Morgan², Donny W. Suh ${ }^{2,3}$, Elise K. Morgan ${ }^{4}$ \\ ${ }^{1}$ University of Nebraska Medical Center, Omaha, NE, USA \\ ${ }^{2}$ Department of Ophthalmology and Visual Sciences, Truhlsen Eye Institute, University of Nebraska Medical Center, Omaha, NE, USA \\ ${ }^{3}$ Children's Hospital \& Medical Center, Omaha, NE, USA \\ ${ }^{4}$ Independent Contractor, Omaha, NE, USA \\ Email:lin.luo@unmc.edu
}

How to cite this paper: Luo, L., Morgan, L.A., Suh, D.W. and Morgan, E.K. (2017) The Suh Muscle Hook: A New Muscle Hook for Tight Extraocular Muscles during Strabismus Surgery. Open Journal of Ophthalmology, 7, 51-56.

https://doi.org/10.4236/ojoph.2017.71008

Received: January 8, 2017

Accepted: February 13, 2017

Published: February 16, 2017

Copyright (c) 2017 by authors and Scientific Research Publishing Inc. This work is licensed under the Creative Commons Attribution International License (CC BY 4.0).

http://creativecommons.org/licenses/by/4.0/

\begin{abstract}
Purpose: To introduce an advanced muscle hook to decrease risks and create more feasible extraocular muscle surgeries for physicians. Case Report: Tight extraocular muscles during strabismus surgery could be extremely challenging even in experienced hands due to restricted globe rotation, limited view, and lack of muscle elasticity. Although a variety of surgical instruments have been introduced through the years, traditional muscle hooks such as the Jameson hook are largely unchanged and are bulky and cumbersome. Using the traditional muscle hook under situations such as pediatric strabismus surgery with smaller eyes and extraocular muscles may increase the risk of perforating the globe or even rupturing the muscles. We developed the "Suh muscle hook", which has a $0.55 \mathrm{~mm}$ wide grooved track in a $1.1 \mathrm{~mm}$ wide horizontal bar, a semi-sharp dissecting tip, and a 30-degree bending near the handle accommodating for nasal bridge to better facilitate surgeons dealing with tight extraocular muscles and minimize risks during strabismus surgery.
\end{abstract}

\section{Keywords}

Suh Muscle Hook, Strabismus Surgery, Extraocular Muscles

\section{Introduction}

Numerous pathological conditions can give rise to tight extraocular muscles, including Graves' disease, congenital fibrosis of extraocular muscles (CFEOM), previous strabismus surgery or retinal procedure (scleral buckle), and traumatic scarring [1] [2]. As well, tight rectus muscles are common findings with Duane's and Mobius' syndromes [3] [4]. 
Surgical recession of tight extraocular muscle can be challenging due to restricted globe rotation which may prevent the optimal muscle exposure required for surgery [5]. Passing a needle anterior to the hook can be difficult due to the inability to stretch the taut muscle to provide enough space for the needle, which may result in additional resection or rupture of an already tight muscle [6] [7] [8]. Tight extraocular muscles often indent the globe and cause scleral thinning in that area [5]. Therefore, passing the needle posterior to the hook in the areas of scleral thinning could increase the risk of globe perforation [7] [8] [9]. A new grooved muscle hook, the Suh muscle hook, has been developed to minimize the perforation risk and improve the success rate of the surgery.

\section{Methods and Material}

The new type of muscle hook (Suh strabismus muscle hook, Ambler Surgical) is primarily used in surgery on tight extraocular muscles. The original model was presented at the AAPOS 2010 Meeting. Modifications have been made to the traditional muscle hook to address the above-mentioned challenges and make it easier to use (Figure 1). Over 100 patients have been treated using the Suh strabismus muscle hook.

The overall length of the instrument is $125 \mathrm{~mm}$ (Figure $2 \mathrm{~A}$ ) with a textured handle for better grasp (Figure $2 \mathrm{~B}$ ). In contrast, the Jameson muscle hook is approximately $133 \mathrm{~mm}$ long. Approximately $105 \mathrm{~mm}$ from the end, the handle has a 30 degree angle to accommodate the nasal bridge for maximal muscle exposure (Figure $2 \mathrm{C}$ ).

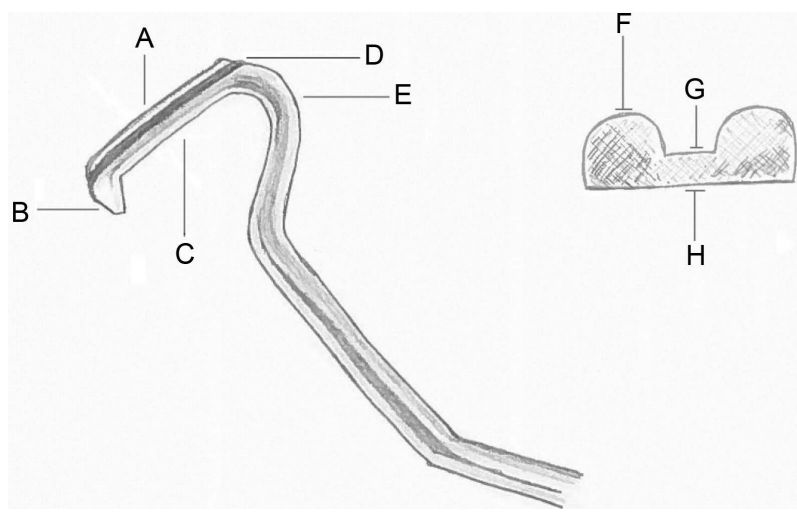

Figure 1. An artist's rendition of the Suh muscle hook. Frontal view: A. Distal horizontal bar. B. Tip. C. Proximal horizontal bar. D. Grooved track. E. Heel. Cross-sectional view of the horizontal bar: F. Anterior surface. G. Groove floor. H. Posterior surface.

\section{A}

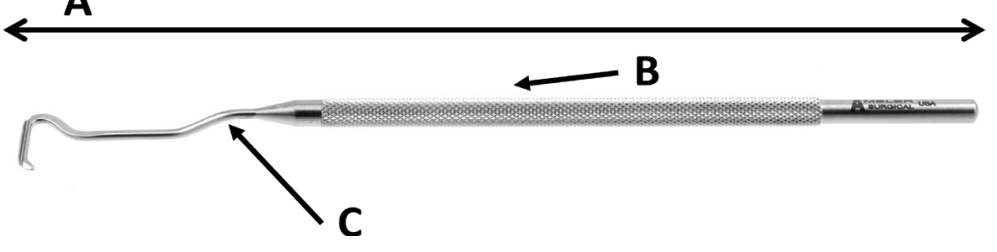

Figure 2. Suh muscle hook. A. Length of $125 \mathrm{~mm}$. B. Textured handle. C. 30-degree angle to accommodate for nasal bridge. 
The horizontal bar (Figure $3 \mathrm{~A}$ ) of the instrument is $8 \mathrm{~mm}$ long, slightly shorter than the traditional Jameson hook of $10 \mathrm{~mm}$ in length. Viewed from the top, the width of the horizontal bar's tip is tapered from $0.8 \mathrm{~mm}$ to $0.2 \mathrm{~mm}$ at the very end of the bar. The semi-sharpened, knobbed tip is $2.0 \mathrm{~mm}$ high to prevent muscle slippage once the muscle is engaged and can be used to dissect additional scleral indentation to provide better isolation of the muscle (Figure $3 \mathrm{~B}$ ).

The $1.1 \mathrm{~mm}$ wide horizontal bar has a $0.55 \mathrm{~mm}$-wide grooved track to provide needle space between the muscle and sclera for safer suturing (Figure $4 \mathrm{~A}$ ). The groove floor has a $0.3 \mathrm{~mm}$-thick metal bridge plate (from the bridge plate floor to the posterior surface of the horizontal bar, Figure $1 \mathrm{G}$ ) which provides enough strength to avoid bending or breaking of the horizontal hook. The bridge plate guides the needle pass, protecting the eye from inadvertent puncture of the thin sclera, while providing consistent suture placement with respect to the scleral insertion.

\section{Discussion}

During strabismus surgery, a standard strabismus hook (e.g. Jameson) requires

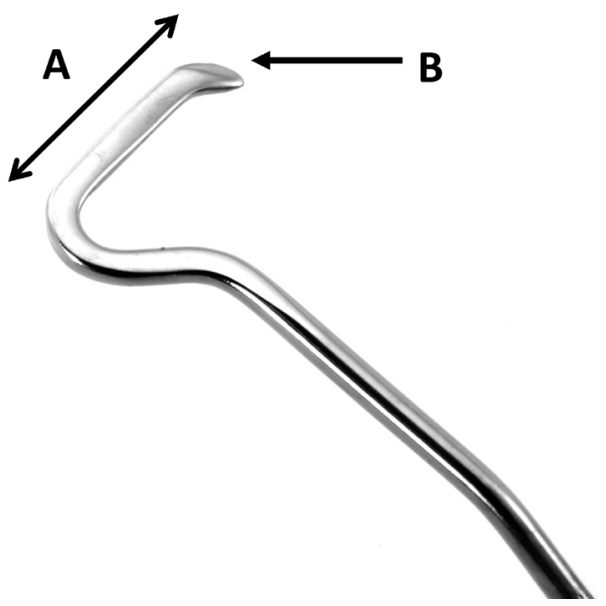

Figure 3. Suh muscle hook. A. The horizontal bar is 8 $\mathrm{mm} \cdot$ long. B. The sharpened, knobbed tip is $2 \mathrm{~mm}$ high.

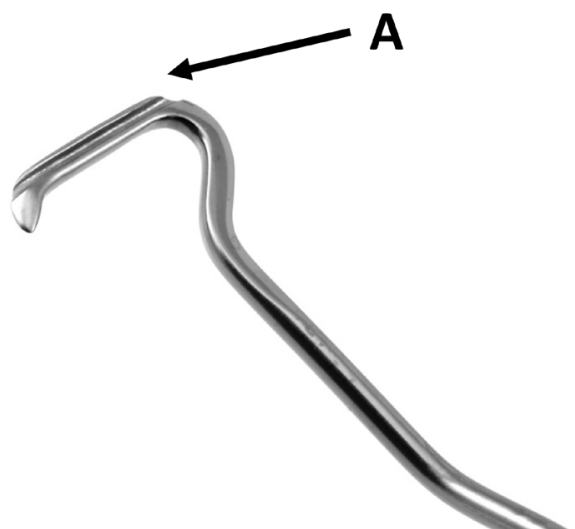

Figure 4. Suh muscle hook. A. $0.55 \mathrm{~mm}$-wide grooved track which is $0.3 \mathrm{~mm}$ thick groove floor. 
the surgeon to lift the muscle upwards off of the sclera to allow space to suture between the hook and sclera [1]. However, tight extraocular muscles, lack of rotation of the globe and the lack of elasticity of the muscle may preclude this maneuver. Furthermore, placing such tension on the muscle may result in muscle rupture, especially in elderly patients [8]. To improve surgical success and decrease surgical risks, numerous improvements were done on the traditional strabismus hook including length and width of the hook's horizontal bar, width of the hook tip, presence of a needle groove and curve of the handle. While other grooved hooks are available, these existing grooved hooks are larger than ordinary hooks and can be difficult to pass under very tight muscles.

The horizontal bar of the Suh strabismus muscle hook is shorter at $8 \mathrm{~mm}$ in length than the Jameson hook of $10 \mathrm{~mm}$ to allow it to fit into tighter spaces but still long enough to encompass the entire muscle. As well, the hook is tapered from $0.8 \mathrm{~mm}$ to $0.2 \mathrm{~mm}$ at the knobbed tip to make it easier to advance the hook tip into a tighter space while simultaneously dissecting under the muscle (Figure $5)$.

During surgery with the Suh strabismus hook, needles can be safely placed within the $0.55 \mathrm{~mm}$ grooved track (Figure 6(a) \& Figure 6(b)). The groove allows for safer suture passes underneath the muscle for full-thickness central security knot at each edge of the muscle. The sharpened and knobbed tip facilitates isolating the muscle from the sclera.

When the Suh muscle hook is rotated in very tight muscles with adhesions, the hook separates the muscle from the underlying sclera to secure it $1 \mathrm{~mm}$ posterior to the insertion. This allows the surgeon to secure the muscle at the optimal position, avoiding unnecessary resection and leaving room to detach the muscle without perforating the globe. Furthermore, the curved 30-degree bend near the hook handle accommodates the nasal bridge to facilitate maximal exposure of the muscle into the surgical field rather than up away from the sclera as by Jameson hook (Figure 7). In addition, the hook is made for right- and left-handed surgeons for their convenience.

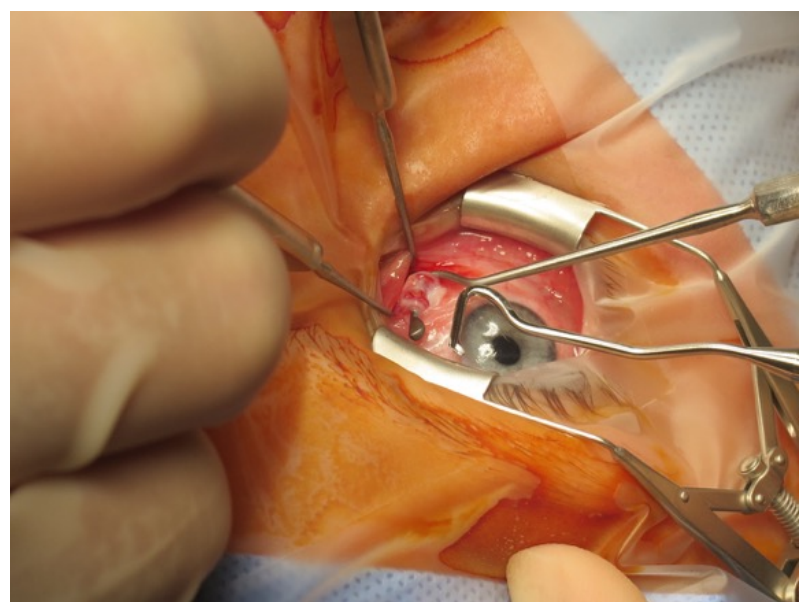

Figure 5. Jameson hook (left) and Suh hook (right) comparison. Note the groove and sharpened tip of the Suh hook. 


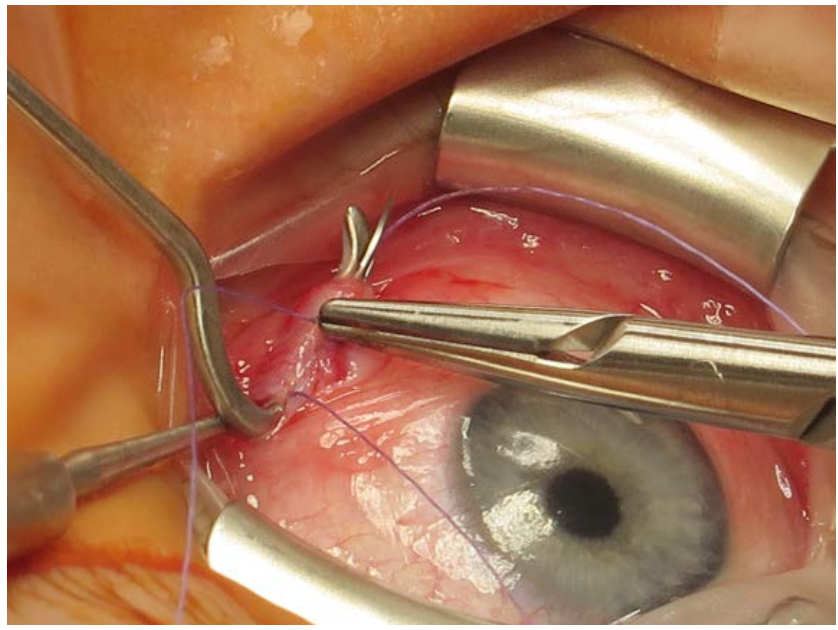

(a)

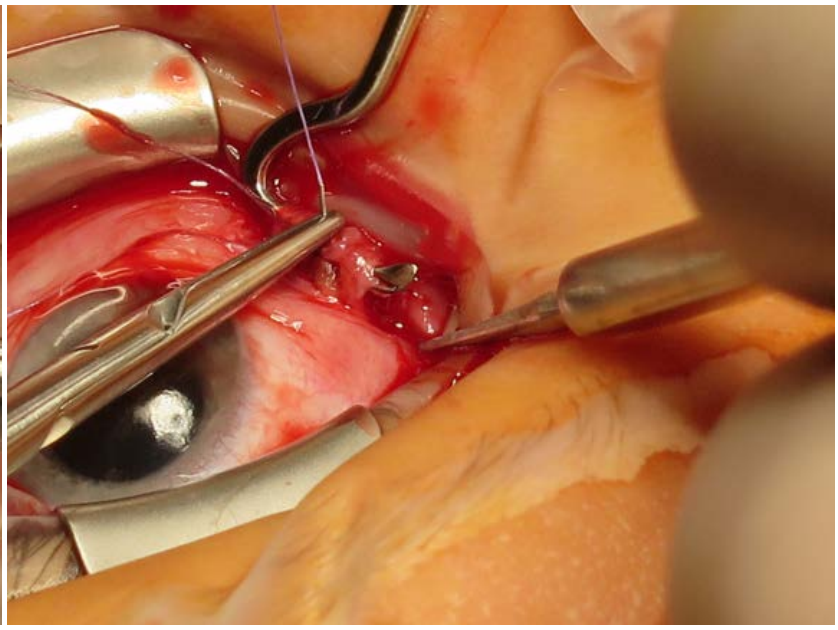

(b)

Figure 6. (a) Needle passing through the groove during right medial rectus recession. (b) Needle passing through the groove during left medial rectus recession.

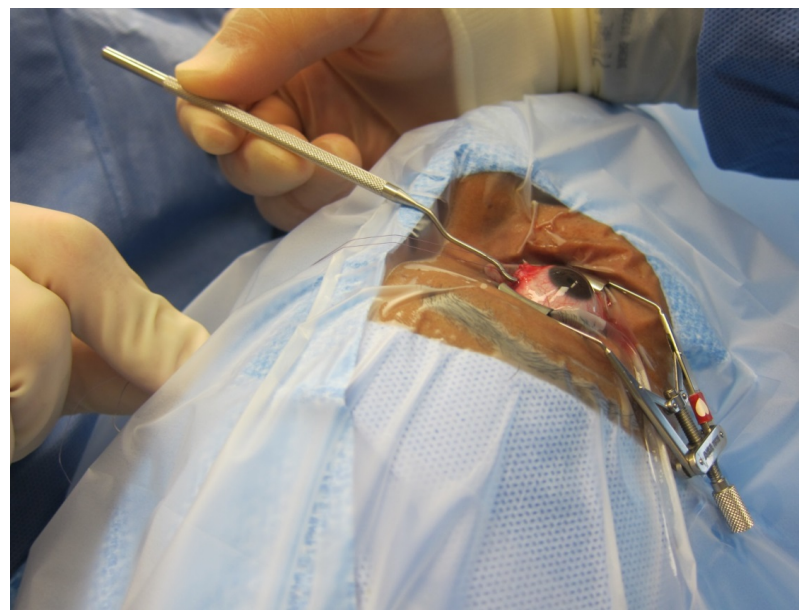

Figure 7. A 30-degree bending near the hook handle accommodates for the nasal bridge height to allow the surgeon maximum exposure to rotate the hook away from the surgical field.

The cost of the Suh muscle hook is slightly higher than the traditional muscle hook and is determined by the manufacturer. The new hook is comparable in price to other newly-designed muscle hooks. The benefits of using the Suh muscle hook include the ability to accommodate the nasal bridge and the increased ease of manipulating the muscle from the sclera. These benefits outweigh the slight increase in cost of the instrument. As well, there is no increase in hospital stay or fees to the patient.

\section{Conclusion}

The new muscle hook is especially helpful for tight extraocular muscles during strabismus surgery. With parameters such as a thinner and, therefore, sharper tip, hook advancement under the muscle is easier. The addition of a 30-degree 
bending in the handle allows for ease of muscle movement. The easy-to-see needle groove allows for safer passage of the needle during suturing. The combination of factors allows for a more precise and less risky strabismus surgery.

\section{Conflict of Interest}

There is no financial interest or conflicts of interest in this paper or the production of this instrument.

\section{References}

[1] Wright, K.W. and Thompson, L. (2007) Color Atlas of Strabismus Surgery. Chapter 10, Springer Science Business Media, LLC., New York.

[2] Harrad, R. (2015) Management of Strabismus in Thyroid Eye Disease. Eye, 29, 234237. https://doi.org/10.1038/eye.2014.282

[3] Barbe, M.E., Scott, W.E. and Kutschke, P.J. (2004) A Simplified Approach to the Treatment of Duane's Syndrome. British Journal of Ophthalmology, 88, 131-138. https://doi.org/10.1136/bjo.88.1.131

[4] Rosenbaum, A.L. (2004) The Efficacy of Rectus Muscle Transposition Surgery in Esotropic Duane Syndrome and VI Nerve Palsy. Journal of American Association for Pediatric Ophthalmology and Strabismus, 8, 409-419. https://doi.org/10.1016/j.jaapos.2004.07.006

[5] Metz, H.S. and Ford, G.P. (1974) The Surgical Approach to Strabismus with Tight Extraocular Muscles. Annals of Ophthalmology, 6, 1237-1241.

[6] Yurdakul, N.S. and Koç, F. (2014) Ocular Complications of Strabismus Surgery. Surgical Science, 5, 397. https://doi.org/10.4236/ss.2014.59064

[7] Olsen, T.W., Aaberg, S.Y., Geroski, D.H. and Edelhauser, H.F. (1998) Human Sclera: Thickness and Surface Area. American Journal of Ophthalmology, 125, 237-241. https://doi.org/10.1016/S0002-9394(99)80096-8

[8] Awad, A.H., Mullaney, P.B., Al-Hazmi, A., Al-Turkmani, S., Wheeler, D., Al-Assaf, M., Awan, M., Zwaan, J.T. and Al-Mesfer, S. (2000) Recognized Globe Perforation during Strabismus Surgery: Incidence, Risk Factors, and Sequelae. Journal of American Association for Pediatric Ophthalmology and Strabismus, 4, 150-153. https://doi.org/10.1016/S1091-8531(00)70004-8

[9] Morris, R.J., Rosen, P.H. and Fells, P. (1990) Incidence of Inadvertent Globe Perforation during Strabismus Surgery. British Journal of Ophthalmology, 74, 490-493. https://doi.org/10.1136/bjo.74.8.490 
Submit or recommend next manuscript to SCIRP and we will provide best service for you:

Accepting pre-submission inquiries through Email, Facebook, LinkedIn, Twitter, etc. A wide selection of journals (inclusive of 9 subjects, more than 200 journals)

Providing 24-hour high-quality service

User-friendly online submission system

Fair and swift peer-review system

Efficient typesetting and proofreading procedure

Display of the result of downloads and visits, as well as the number of cited articles Maximum dissemination of your research work

Submit your manuscript at: http://papersubmission.scirp.org/

Or contact ojoph@scirp.org 